\title{
Assessment of coronary artery disease and calcified coronary plaque burden by computed tomography in patients with and without diabetes mellitus
}

\author{
Erica Maffei • Sara Seitun • Koen Nieman • Chiara Martini • Andrea Igoren Guaricci • \\ Carlo Tedeschi • Annick C. Weustink • Nico R. Mollet • Elena Berti • Roberto Grilli • \\ Giancarlo Messalli • Filippo Cademartiri
}

Received: 26 February 2010 /Revised: 12 September 2010 / Accepted: 18 September 2010 /Published online: 10 November 2010

(C) The Author(s) 2010. This article is published with open access at Springerlink.com

\begin{abstract}
Purpose To compare the coronary atherosclerotic burden in patients with and without type-2 diabetes using CT Coronary Angiography (CTCA).

Methods and Materials 147 diabetic (mean age: 65t 10 years; male: 89) and 979 nondiabetic patients (mean
\end{abstract}

E. Maffei $\cdot$ S. Seitun $\cdot$ C. Martini $\cdot$ F. Cademartiri

Department of Radiology and Cardiology,

Azienda Ospedaliero-Universitaria di Parma,

Parma, Italy

K. Nieman • C. Martini - A. C. Weustink - N. R. Mollet •

F. Cademartiri

Department of Radiology and Cardiology,

Erasmus Medical Center,

Rotterdam, The Netherlands

A. I. Guaricci

Department of Cardiology,

Azienda Ospedaliero-Universitaria di Foggia,

Foggia, Italy

C. Tedeschi

Department of Cardiology, Ospedale San Gennaro,

Naples, Italy

E. Berti $\cdot$ R. Grilli

Healthcare and Social Agency, Regione Emilia-Romagna,

Bologna, Italy

G. Messalli

SDN Foundation-IRCCS,

Naples, Italy

F. Cademartiri $(\square)$

Department of Radiology,

Azienda Ospedaliero-Universitaria-Parma,

43100 Parma, Italy

e-mail: filippocademartiri@hotmail.com age: $61 \pm 13$ years; male: 567$)$ without a history of coronary artery disease (CAD) underwent CTCA. The per-patient number of diseased coronary segments was determined and each diseased segment was classified as showing obstructive lesion (luminal narrowing $>50 \%$ ) or not. Coronary calcium scoring (CCS) was assessed too.

Results Diabetics showed a higher number of diseased segments $(4.1 \pm 4.2$ vs. $2.1 \pm 3.0 ; p<0.0001)$; a higher rate of CCS $>400(p<0.001)$, obstructive CAD ( $37 \%$ vs. $18 \%$ of patients; $p<0.0001)$, and fewer normal coronary arteries ( $20 \%$ vs. $42 \% ; p<0.0001)$, as compared to nondiabetics. The percentage of patients with obstructive CAD paralleled increasing CCS in both groups. Diabetics with $\mathrm{CCS} \leq 10$ had a higher prevalence of coronary plaque (39.6\% vs. $24.5 \%, p=0.003)$ and obstructive CAD (12.5\% vs. $3.8 \%, p=0.01)$. Among patients with $\mathrm{CCS} \leq 10$ all diabetics with obstructive CAD had a zero CCS and one patient was asymptomatic.

Conclusions Diabetes was associated with higher coronary plaque burden. The present study demonstrates that the absence of coronary calcification does not exclude obstructive CAD especially in diabetics.

Keywords Diabetes mellitus · Coronary artery disease . CT coronary angiography

\section{Introduction}

Over the past decades type-2 diabetes mellitus (DM) has become a major public health concern. The World Health Organization estimates that worldwide 220 million people have diabetes, a number that may double by the year 2030 [1]. Diabetic patients have a higher prevalence of coronary 
heart disease and are more likely to develop myocardial infarction compared to those without diabetes. The risk of myocardial infarction or coronary death in type 2 diabetics is similar to patients with a history of myocardial infarction [2]. Frequently, diabetic patients with objective coronary heart disease have blunted or atypical symptoms, thought to be related to autonomic denervation of the heart [3].

Non-enhanced, ECG-synchronized CT imaging of the heart can image calcified atherosclerotic plaque in the coronary arteries $[4,5]$. The amount of coronary calcium on $\mathrm{CT}$, which correlates with the global coronary plaque burden [6], was demonstrated to be significantly higher in diabetic patients, reflecting the higher prevalence of (preclinical) coronary atherosclerosis [7, 8]. More recently contrast-enhanced CT coronary angiography (CTCA) has emerged as a non-invasive means to diagnose coronary artery stenosis [9]. As CTCA also visualizes non-calcified plaque in addition to calcified plaque material in the vessel wall, contrast-enhanced CT allows more complete evaluation of the total plaque burden [10].

In this cross-sectional study we compared the presence of obstructive and non-obstructive CAD as well as calcified coronary artery plaque burden in a total of 1126 patients with and without diabetes mellitus.

\section{Material and methods}

\section{Population}

Over a 2-year period 1126 consecutive patients with suspected CAD but no history of coronary artery disease (prior myocardial infarction or myocardial revascularization procedure) underwent CTCA at our institute. The study was a single-centre prospective observational study. Reasons for referral included angina, high-risk profile without symptoms or nonconclusive stress test results. Detailed information regarding symptoms, physical examination, medical history and risk factors were collected prospectively at the time of presentation. The population included 147 patients (13\%) with diabetes, defined as a fasting plasma glucose level of $\geq 126 \mathrm{mg} / \mathrm{dL}$ treated either by dietary intervention, oral glucose-lowering medication or insulin [11]. Chest pain symptoms were classified as typical, atypical and non-anginal, according to the criteria by Diamond \& Forrester [12]. The category "other sympoms" included dyspnea.

Pre-test likelihood of CAD was determined in every patient according to a modification of the DiamondForrester algorithm, as published by Morise et al. [13]. These patients were further categorized into low probability (score $0-8$ ), intermediate probability (score 9-15), and high probability (score $>15$ ).
Patients only underwent CTCA in the absence of an irregular heart rate, pregnancy, a known contrast allergy or renal insufficiency (creatinine clearance $<60 \mathrm{~mL} / \mathrm{min}$ ), respiratory conditions preventing a $12 \mathrm{~s}$ breath hold, or unstable clinical conditions. The study was approved by the Medical Ethics Committee and informed consent was obtained from all participating patients before testing.

\section{CT coronary angiography}

All examinations were performed using 64-slice CT (Sensation 64, Siemens, Forchheim, Germany). To assess the coronary calcium burden, non-enhanced ECG-triggered CT was performed: collimation $20 \times 1.2 \mathrm{~mm}, 120 \mathrm{kV}$, $150 \mathrm{mAs}$, estimated dose $1.5 \mathrm{mSv}$.

All examinations were performed using 64-slice CT (Sensation 64, Siemens, Forchheim, Germany). A coronary calcium score (CCS) was calculated according to the Agatston method [14] using semiautomatic software available on the workstation (Siemens HeartView, Forchheim, Germany).

CT coronary angiography was performed using a retrospectively ECG-gated protocol with ECG-controlled tube current modulation: collimation $64(32 \times 2) \times 0.6 \mathrm{~mm}$, $120 \mathrm{kV}, 800-950 \mathrm{mAs}$, rotations time $0.33 \mathrm{~s}$, estimated radiation dose $8-13 \mathrm{mSv}$, after injection of $80-100 \mathrm{ml}$ of iomeprol $400 \mathrm{mgI} / \mathrm{ml}$ (Iomeron, Bracco, Italy) at 4-6 ml/s, using automatic bolus tracking to synchronize CT data acquisition with the passage of the contrast medium. Images were reconstructed during mid-diastole and/or end-systole: slice thickness $0.75 \mathrm{~mm}$, reconstruction interval $0.4 \mathrm{~mm}$, medium smooth filtering (B30f). In the absence of contra-indications $5-10 \mathrm{mg}$ atenolol was intravenously administrated to patients with a heart rate $>65 / \mathrm{min}$. All received sublingual nitroglycerin $(0.3 \mathrm{mg})$ just before the scan.

Two independent, observers, blinded with regard to the patients' clinical background, evaluated all CT angiograms, with disagreeing results resolved in a joint consensus reading. Each of 16 coronary segments [15] was first assessed for image quality and interpretability. Per interpretable coronary segments the presence of atherosclerotic plaque, defined as structures $\geq 1 \mathrm{~mm}$ in diameter within the vessel wall adjacent to the coronary artery lumen but distinguishable from the perivascular tissues, was assessed using axial images and multiplanar reformations [4]. The segmental stenosis severity was visually estimated and classified as obstructive $(>50 \%$ luminal diameter narrowing) or non-obstructive $(\leq 50 \%$ luminal narrowing).

Statistical analysis

Categorical variables are described as frequencies (percentage), continuous variables as mean $( \pm \mathrm{SD})$ or median 
(interquartile range) respectively for normally and not normally distributed variables. Groups were compared using the Student $t$ and Chi-square or Fisher exact tests, as appropriate. Because coronary artery calcium score had highly skewed, non-normal distributions, the Mann-Whitney $U$ test was used to compare coronary artery calcium scores between diabetic and nondiabetic subjects.

To assess the range and the severity of CAC burden, patients were divided into five categories, as previously reported [16]: less than or equal to 10 (negative or minimal CCS), 11-100 (mild CCS), 101-400 (moderate CCS), 4011000 (severe CCS), and greater than 1000 (extensive CCS). Furthermore, the relationship between the calcium score stratified in three groups $(0-10,11-100,>100)$ and coronary artery disease on CTCA was assessed.

To determine the association between CTCA variables and the presence of diabetes, linear regression analysis was performed for continuous dependent variables, logistic regression analysis for categorical dependent variables. Univariate analysis was followed by multivariate analysis with adjustment for: age, gender, traditional risk factors for CAD (hypertension, hypercholesterolemia, obesity, family history of CAD, smoking) and symptoms (typical angina, atypical angina and other symptoms). A forward stepwise multiple linear or logistic regression analysis was used, with a required variable significance of 0.05 to be included into the model, and a cut-off value of 0.1 for exclusion.
Variables with a significance below 0.05 in the final model were included in this model. Odds ratios or estimates of correlation were estimated with a $95 \%$ confidence intervals. Statistical analysis was performed with dedicated software (SPSS 12.0, SPSS Inc., USA).

\section{Results}

Patient characteristics

CTCA was performed without complications in all 1126 patients: $58 \%$ male, $61 \pm 13$ years (Table 1). Overall, 165 (15\%) patients had low, 609 (54\%) had intermediate, and $352(31 \%)$ had high pre-test likelihood of CAD. Diabetic patients were older $(65 \pm 11$ years vs. $61 \pm 13$ years, $p=$ $0.0003)$, had a higher BMI (28.7 vs. $26.5, p<0.0001)$, compared to non-diabetics, as well as a larger number of traditional risk factors; 2.4 versus 1.9 , including hypertension, hypercholesterolemia and obesity, in addition to diabetes mellitus. Diabetic subjects who underwent a functional stress test before CTCA, such as exercise treadmill or pharmacological stress imaging testing (myocardial perfusion imaging and stress echocardiography), showed a higher rate of non-conclusive test results compared to non-diabetics: $39 \%(n=33 / 85)$ vs. $26 \%(n=$ $162 / 620), p=0.02$.

Table 1 Baseline characteristics

Data are presented as number (percentage) of subjects or the mean value \pm SD. Body-mass index (BMI). ${ }^{\mathrm{a}}$ Variables were compared between diabetic and non-diabetic patients using the independent samples $t$ test and Pearson's chi-square test, as appropriate. ${ }^{\mathrm{b}}$ According to the scoring method of Morise.

\begin{tabular}{|c|c|c|c|c|}
\hline & $\begin{array}{l}\text { All patients } \\
(n=1126)\end{array}$ & $\begin{array}{l}\text { Diabetics } \\
(n=147)\end{array}$ & $\begin{array}{l}\text { Non-diabetics } \\
(n=979)\end{array}$ & $p$ Value $^{\mathrm{a}}$ \\
\hline \multicolumn{5}{|l|}{ Clinical characteristics } \\
\hline Age (years; mean $\pm \mathrm{SD}$ ) & $61.4 \pm 12.6$ & $64.9 \pm 10.5$ & $60.9 \pm 12.8$ & 0.0003 \\
\hline Male gender $(\%)$ & $656(58)$ & $89(60)$ & $567(58)$ & 0.6 \\
\hline $\mathrm{BMI}\left(\mathrm{kg} / \mathrm{m}^{2} ;\right.$ mean $\left.\pm \mathrm{SD}\right)$ & $26.8 \pm 4.3$ & $28.7 \pm 4.4$ & $26.5 \pm 4.2$ & $<0.0001$ \\
\hline Mean heart rate $\left(\mathrm{min}^{-1} \pm \mathrm{SD}\right)$ & $62.6 \pm 11.8$ & $63.6 \pm 12.4$ & $62.5 \pm 11.7$ & 0.29 \\
\hline \multicolumn{5}{|l|}{ Risk factors } \\
\hline Number of risk factors (mean \pm SD) & $2.0 \pm 1.2$ & $2.4 \pm 1.2$ & $1.9 \pm 1.2$ & $<0.0001$ \\
\hline Hypertension (\%) & $671(60)$ & $105(71)$ & $566(58)$ & 0.002 \\
\hline Hypercholesterolemia (\%) & $484(43)$ & $76(52)$ & $408(42)$ & 0.027 \\
\hline Obesity $\left(\mathrm{BMI} \geq 30 \mathrm{~kg} / \mathrm{m}^{2}\right)(\%)$ & $231(20)$ & $54(37)$ & $177(18)$ & $<0.0001$ \\
\hline Current smoking (\%) & $356(32)$ & $50(34)$ & $306(31)$ & 0.56 \\
\hline Family history of coronary disease (\%) & $530(47)$ & $69(47)$ & $461(47)$ & 0.95 \\
\hline \multicolumn{5}{|l|}{ Symptoms } \\
\hline Typical angina pectoris $(\%)$ & $271(24)$ & $26(18)$ & $240(25)$ & 0.08 \\
\hline Atypical angina pectoris $(\%)$ & $335(30)$ & $47(32)$ & $288(29)$ & 0.59 \\
\hline Non-anginal or other symptoms (\%) & $224(20)$ & $43(29)$ & $186(19)$ & 0.005 \\
\hline Asymptomatic (\%) & $296(26)$ & $31(21)$ & $265(27)$ & 0.15 \\
\hline \multicolumn{5}{|l|}{ Pre-test likelihood of $\mathrm{CAD}^{\mathrm{b}}$} \\
\hline Low $(\%)$ & $165(15)$ & $5(3)$ & $160(16)$ & 0.0001 \\
\hline Intermediate $(\%)$ & $609(54)$ & $62(42)$ & $547(56)$ & 0.002 \\
\hline High $(\%)$ & $352(31)$ & $80(54)$ & $272(28)$ & $<0.0001$ \\
\hline
\end{tabular}


Furthermore, diabetics more frequently presented with non-anginal or other symptoms such as dyspnea respect to nondiabetics $(29 \%$ vs. $19 \%, p=0.005)$. The mean heart rate during the scan was $63 \pm 12 \mathrm{bpm}$, and not different between patients with and without diabetes $(p>0.05)$.

Coronary plaque and stenosis

For CTCA diagnostic image quality was achieved in 16,907 out of 17,017 coronary segments $(99.4 \%)$. Image quality was considered non-diagnostic in $110(0.6 \%)$ segments: 91 related to motion artefacts, 19 to severe calcification, which were excluded from further evaluation (Table 2, Figs. 1 and 2). Diabetics had a higher prevalence of any coronary artery atherosclerosis (perpatient) compared to non-diabetics: $80 \%(n=118)$, vs. $58 \%$ $(n=567)$, respectively $(p<0.0001)$; and a higher prevalence of obstructive coronary disease: $37 \%(n=55)$, vs. $18 \%(n=173)$, respectively, $p<0.0001$ (Fig. 1). Per patient the number of segments with plaque was higher for those with diabetes: 4.1 vs. 2.1 , respectively $(p<0.0001)$; as well as the number of segments with obstructive disease: 0.8 vs. 0.4 , respectively, $p=0.0001$ (Fig. 2). Multivessel disease was seen more often in patients with diabetes: $15 \%$ $(n=22)$, vs. $7 \%(n=62)$, respectively $(p=0.0004)$ (Table 2$)$. Prevalence of non-obstructive and obstructive CAD on CTCA in DM and non DM patients stratified for the type of presenting symptom are provided in Table 3. In both DM and non DM patients, the higher prevalence of obstructive CAD was documented in patients with typical angina ( $46 \%$ vs. $28 \%$, respectively, $p=$ n.s.). Moreover, diabetics compared to nondiabetics showed an higher prevalence of obstructive CAD among the other clinical categories.
Coronary calcium

The median Agatston calcium score was higher in diabetic patients: 124.4 (interquartile range: 0-658.8), versus 0 (interquartile range: $0-112.8)$, respectively, $(p<$ $0.0001)$. Only $29 \%(n=43)$ of the diabetics, compared to $47 \%(n=458)$ of the non-diabetics had a negative calcium score $(p=0.0001)$. Furthermore, only $4 \%(n=5)$ of diabetics vs $9 \%(n=88)$ of non-diabetics showed minimal CCS (1-10), $p=0.03$. Consequently, higher calcium scores $(>400)$ were more prevalent among diabetic patients respect to non-diabetics ( $n=50 / 147,34 \%$ vs $n=108 / 979$, $11 \%, p<0.0001$ ), (Fig. 3). For patients with a low or negative calcium score $(\leq 10)$, CTCA shows that those with diabetes had a higher prevalence of coronary atherosclerosis: $39.6 \% \quad(n=19 / 48)$ vs. $24.5 \% \quad(n=134 /$ 546), $p=0.003$, as well as more obstructive CAD: $12.5 \%$ $(n=6 / 48)$ vs. $3.8 \%(n=21 / 546), p=0.01$, compared to nondiabetics (Fig. 4). Notably, among patients with CCS from 0 to 10 , all 6 diabetic subjects $(100 \%)$ with obstructive CAD on CTCA had negative CCS, whereas only $43 \% \quad(n=9 / 21)$ of non-diabetics with obstructive $\mathrm{CAD}$ had $\mathrm{CCS}=0$. Correspondingly, among patients with negative CCS, $14 \%$ of diabetics $(n=6 / 43)$ and $2 \%$ of nondiabetics $(n=9 / 458)$ showed obstructive CAD, $p<0.0001$. Furthermore, after stratification by presenting symptoms, diabetic patients with negative CCS and typical pain showed a higher prevalence of non-obstructive (noncalcific) CAD respect to non-diabetics: $50 \%(n=4 / 8)$ vs $10 \%(n=10 / 97), p<0.05$ (Table 4). Although diabetics with $\mathrm{CCS}=0$ showed a trend towards higher prevalence of obstructive CAD among symptom categories, not statistically significant differences between groups were observed.
Table 2 CTCA findings in patients with and without diabetes

\footnotetext{
${ }^{\text {a }}$ Diabetic and nondiabetic patients were compared using the Pearson's chi-square test (for percentages), independent samples $t$ test (for mean CAC score), and MannWhitney $U$ test (for median CAC score). Data are presented as number (percentage) of subjects, the mean value $\pm \mathrm{SD}$ or median value (IQR: interquartile range).
}

\begin{tabular}{lllc}
\hline & $\begin{array}{l}\text { Diabetics } \\
(n=147)\end{array}$ & $\begin{array}{l}\text { Nondiabetics } \\
(n=979)\end{array}$ & $p$ Value $^{\mathrm{a}}$ \\
\hline Patients & & & \\
Normal coronary arteries (\%) & $29(20)$ & $412(42)$ & $<0.0001$ \\
Non-obstructive atherosclerosis (\%) & $63(43)$ & $394(40)$ & 0.6 \\
Coronary stenosis (\%) & $55(37)$ & $173(18)$ & $<0.0001$ \\
Single-vessel disease (\%) & $33(22)$ & $111(11)$ & 0.0003 \\
Multivessel disease (\%) & $22(15)$ & $62(7)$ & 0.0004 \\
Calcium score & & & $<0.0001$ \\
mean \pm SD & $437.4 \pm 636.03$ & $161.6 \pm 420.26$ & $<0.0001$ \\
median (IQR) & $124.4(0-658.8)$ & $3(0-112.8)$ & $<0.0001$ \\
Coronary segments & & & $<0.0001$ \\
Atherosclerotic (mean \pm SD]) & $4.1 \pm 4.18$ & $2.1 \pm 3.03$ & 0.0001 \\
Non stenotic (mean [SD]) & $3.3 \pm 3.71$ & $1.7 \pm 2.59$ & $0.4 \pm 1.08$ \\
Stenotic (mean [SD]) & $0.8 \pm 1.48$ & & \\
\hline
\end{tabular}


Diabetics ( $n=147)$

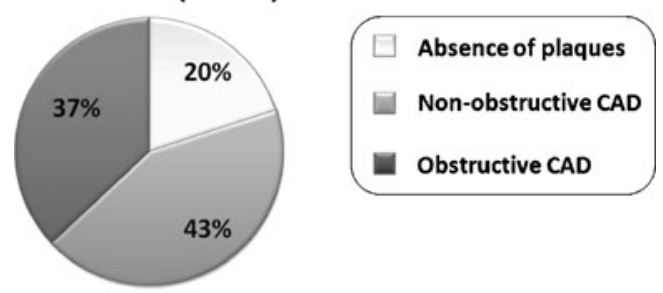

Nondiabetics $(n=979)$

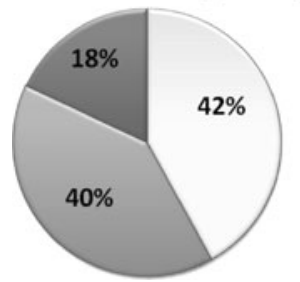

Fig. 1 Prevalence of coronary artery disease (CAD) in patients with and without diabetes mellitus. Per patient prevalence of the absence of detectable CAD $(p<0.0001)$, obstructive disease $(p<0.0001)$, and non-obstructive CAD $(p>0.05)$

Finally, patients with a high calcium score had more obstructive CAD for both diabetics and non-diabetics, without any significant differences between the two groups (Fig. 4).

Association between CT coronary disease and diabetes mellitus

By univariate regression analysis having diabetes was associated with more atherosclerotic plaque, coronary

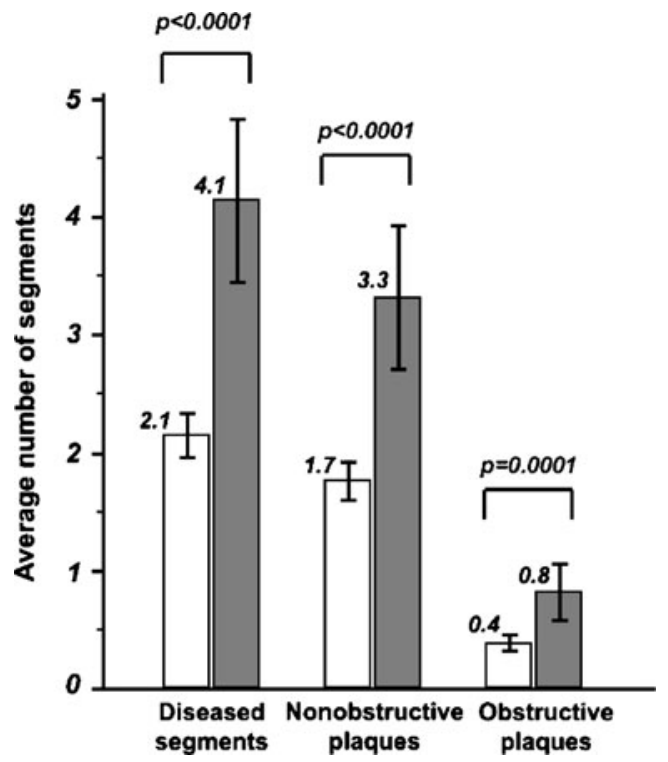

Fig. 2 Segmental coronary artery disease in patients with and without diabetes mellitus. Clustered multiple-variable graph of the number of segments per patient with coronary atherosclerosis, divided in nonobstructive plaque and obstructive coronary disease, for patients with $(\square)$ and without diabetes mellitus $(\square)$ stenosis (per coronary branch), single and multi-vessel disease, higher coronary calcium score, and for patients with a negative or minimal CCS $(\leq 10)$ with the presence of any atherosclerotic plaque or obstruction, as well as the presence of plaque and obstruction per coronary segments $(p<0.05)$ (Table 5). After adjusting for baseline characteristics: age, gender, traditional risk factors for CAD (hypertension, hypercholesterolemia, obesity, family history of CAD, smoking) and symptoms (typical angina, atypical angina and other symptoms), forward stepwise multivariate regression analysis confirmed that all of these variables, except obstructive CAD in the LCX, were independently associated with diabetes.

\section{Discussion}

CT coronary disease and diabetes

An ageing population, suboptimal nutritional habits and increased prevalence of obesity will increase the prevalence of type II diabetes and related health problems, including coronary heart disease $[1,17]$. Indeed in our study patients with diabetes had a significantly higher calcium score compared to non-diabetics. In addition the number of segments per patient with coronary plaque on CTCA was nearly twice as high for diabetic patients, similarly the number of segments with obstructive disease was two times higher compared to patients without diabetes. In the current study with CTCA, coronary atherosclerosis was observed in $80 \%$ of diabetics and almost half showed obstructive CAD. These results are in line with previous observations derived from a large autopsy cohort of 293 diabetic decedents, in which coronary atherosclerosis was observed in almost $75 \%$ of individuals, with $50 \%$ having diffuse multi-vessel CAD [18].

In both diabetic and non-diabetic patients, the higher prevalence of obstructive CAD was documented in patients with typical angina. This finding is in agreement with the seminal work by Diamond and Forrester [19], in which patients with typical angina had a higher likelihood of angiographic CAD than patients with atypical or nonanginal chest pain. Moreover, among the other clinical categories, diabetics showed a two to three times higher prevalence of obstructive CAD as compared to nondiabetics. These results seem to reflect that the prevalence of obstructive CAD is less influenced by symptomatic status in diabetics respect to non-diabetics.

At multiple regression analysis, the increased extent and severity of CAD associated with diabetes was independent of traditional risk factors of cardiovascular disease, which confirms earlier studies in asymptomatic populations [20, 21] as well as symptomatic populations [22-24]. 
Table 3 Prevalence of non-obstructive CAD/obstructive CAD in diabetic and non-diabetic patients among different symptom categories

\begin{tabular}{lrr}
\hline Symptom categories & Diabetics $(n=147)$ & Nondiabetics $(n=979)$ \\
\hline Typical angina pectoris & $12 / 26(46) / 12 / 26(46)$ & $88 / 240(37) / 68 / 240(28)$ \\
Atypical angina pectoris & $21 / 47(45) / 16 / 47(34)^{*}$ & $126 / 288(44) / 35 / 288(12)^{*}$ \\
Non-anginal or other symptoms & $16 / 43(37) / 16 / 43(37)^{*}$ & $72 / 186(39) / 33 / 186(18)^{*}$ \\
Asymptomatic & $14 / 31(45) / 11 / 31(35)^{*}$ & $108 / 265(41) / 37 / 265(14)^{*}$ \\
\hline
\end{tabular}

Data are presented as number/total number (percentage) of subjects.

*Significant difference $(p<0.05)$ between diabetic and non-diabetic patients.

CT coronary angiography and calcium score in diabetic patients with suspected coronary artery disease

The assessment of suspected coronary heart disease is more challenging in diabetic patients because of the atypical nature or absence of chest pain symptoms, more frequent inability to perform an exercise tests and less reliable stress imaging in the presence of obesity or multivessel disease $[25,26]$. Moreover, among the patients referred after a nonconclusive stress test, diabetic patients were overrepresented. CT coronary angiography is considered complementary to stress testing, and for the mentioned reasons may be particularly useful in diabetic patients. While it lacks the diagnostic and prognostic value of the aerobic performance, it adds value in terms of (non-obstructive) plaque imaging. However, the higher calcium may complicate severity assessment of individual lesions.

Since calcium deposition is related to the presence of atherosclerosis, coronary calcifications serve as a direct marker for $\mathrm{CAD}$, and more severe plaques tend to have a greater amount of calcium [27]. In our population-based study, about half of the patients in both groups with CCS $>100$ had obstructive CAD. Furthermore, extensive CCS $(>400)$ was more prevalent in diabetic patients than nondiabetic control subjects ( $34 \%$ vs $11 \%)$. These findings are of interest, as a calcium score higher than 400 is associated with a high risk of myocardial perfusion impairment [28] and a high risk of any cardiovascular

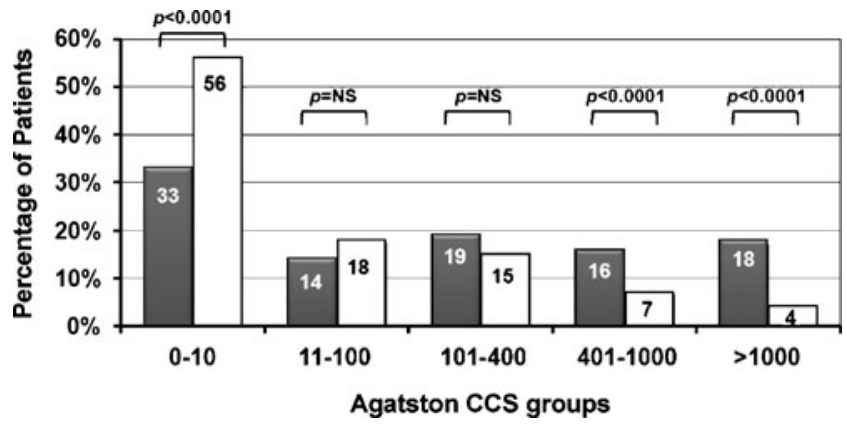

Fig. 3 Coronary calcium score distribution in relation to diabetes mellitus. Bar graph of the distribution of coronary calcium score (CCS) categories for patients with $(\square)$ and without diabetes mellitus $(\square)$ event in the short term [29]. Nevertheless, as recently pointed out [30], it remains important to recognise that for any extent of plaque burden, cardiovascular risk is higher in diabetic patients than in nondiabetic individuals.

The exact prevalence of noncalcified plaque in the absence of any calcium remains to be fully elucidated; previous studies have shown a large variation, which may be explained by differences in study population [31]. In our study we observed a higher rate of plaques and three times more frequent obstructive disease $(12.5 \%$ vs $3.8 \%, p=0.01)$ in diabetic population respect to non-diabetics despite a negative/low calcium score. Previous observations using 64-slice CTCA in patients with stable chest pain syndrome or with suspected acute coronary syndrome (regardless of the presence of diabetes) reported a prevalence of obstructive CAD with zero and low CCS in the range of $6.2-10 \%$ [32-35]. A recent prospective multicenter trial including mainly intermediate-risk patients with suspected CAD and planned clinically-indicated conventional coronary angiography within 30-day from 64-slice CTCA examination, reported a prevalence of $19 \%$ of obstructive CAD among patients with $\mathrm{CCS}=0$ [36]. Taken together these observations suggest that the absence of coronary calcium does not reliably exclude atherosclerosis or even obstructive CAD in

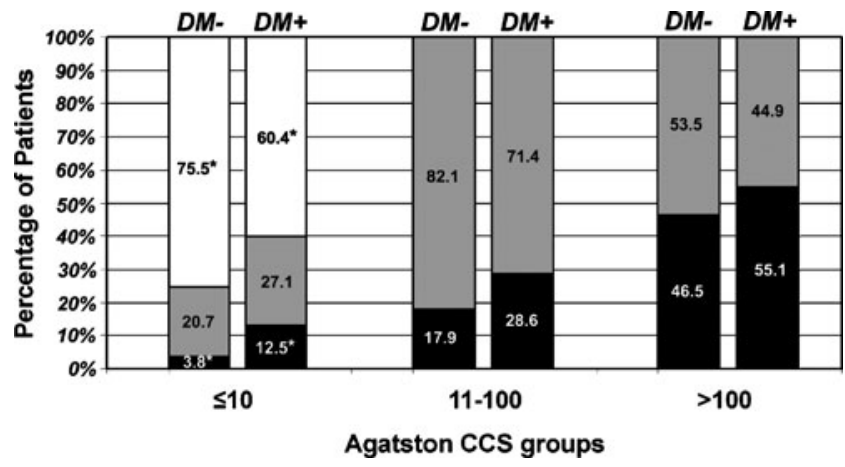

Fig. 4 Association between the coronary calcium score and coronary artery disease on CTCA. Clustered bar graph of the CTCA findings: normal coronary arteries ( $\square$ ), non-obstructive CAD ( $\square$ ), and obstructive CAD ( $\square$ ), for patients with (DM+) and without diabetes mellitus (DM-), divided into three groups according to the coronary calcium score $(\mathrm{CCS}) . *$ =significant differences between diabetics and non-diabetics $(p<0.05)$ 
Table 4 Prevalence of non-obstructive CAD/obstructive CAD in diabetic and non-diabetic patients with $\mathrm{CCS}=0$ among different symptom categories

\begin{tabular}{lrr}
\hline Symptom categories & Diabetics $(n=43)$ & Nondiabetics $(n=458)$ \\
\hline Typical angina pectoris & $4 / 8(50) * / 2 / 8(25)$ & $10 / 97(10) * / 5 / 97(5)$ \\
Atypical angina pectoris & $2 / 14(14) / 2 / 14(14)$ & $18 / 141(13) / 1 / 141(1)$ \\
Non-anginal or other symptoms & $2 / 14(14) / 1 / 14(7)$ & $8 / 90(9) / 2 / 90(2)$ \\
Asymptomatic & $0 / 7(0) / 1 / 7(14)$ & $13 / 130(10) / 1 / 130(1)$ \\
\hline
\end{tabular}

Data are presented as number/total number (percentage) of subjects.

*Significant difference $(p<0.05)$ between diabetic and non-diabetic patients.

patients at high cardiovascular risk and this may be especially true for diabetic subjects.

Detection of preclinical coronary artery disease

Diabetic patients have a much higher risk of cardiovascular events, which qualifies them for intensive preventive management. Considering this high risk of adverse events and stunned anginal symptoms in the presence of obstructive $\mathrm{CAD}$, raises the question whether early detection of CAD is meaningful in diabetics. In the current study, we documented obstructive $\mathrm{CAD}$ in one asymptomatic patient with $\mathrm{CCS}=0$ $(1 / 7,14 \%)$; this observation is in concordance with the study of Sholte et al. which reported a prevalence of obstructive
CAD in $10 \%$ of asymptomatic diabetic patients with minimal calcium $(\mathrm{CCS}<10)$ [20]. Further risk refinement by various non-invasive means has proven difficult. Clinical outcome after a negative stress echocardiography test or myocardial perfusion scan is not equally favourable in diabetic patients, and does not have the same freedom-of-events warranty duration, compared to patients without diabetes [37-39]. The calcium score, which is associated with the total amount of coronary atherosclerosis, predicts cardiovascular events both in diabetic and non-diabetic patients, with incremental predictive value to traditional risk factors [16]. CT angiography provides a more complete representation of the total plaque burden, i.e. imaging both calcified and non-calcified plaque material, in addition to the detection and localization

Table 5 Association between CTCA findings and diabetes mellitus

\begin{tabular}{|c|c|c|c|c|}
\hline \multirow[t]{2}{*}{ CTCA characteristics } & \multicolumn{2}{|l|}{ Univariate } & \multicolumn{2}{|l|}{ Multivariate $^{\mathrm{b}}$} \\
\hline & Parameter estimate & $p$ Value & Parameter estimate & $p$ Value \\
\hline \multicolumn{5}{|l|}{ Patients } \\
\hline Absence of CAD & $0.34(0.22-0.52)$ & $<0.0001$ & $0.42(0.26-0.68)$ & $<0.0001$ \\
\hline Non-obstructive CAD & $1.11(0.78-1.58)$ & 0.55 & - & - \\
\hline Obstructive CAD & $2.78(1.92-4.04)$ & $<0.0001$ & $2.44(1.62-3.68)$ & $<0.0001$ \\
\hline Single-vessel disease & $2.15(1.39-3.34)$ & 0.001 & $1.85(1.16-2.94)$ & 0.01 \\
\hline Multivessel disease & $2.46(1.45-4.18)$ & 0.001 & $2.08(1.20-3.61)$ & 0.009 \\
\hline \multicolumn{5}{|l|}{ Obstructive CAD in } \\
\hline LM/LAD coronary artery & $2.45(1.59-3.78)$ & $<0.0001$ & $2.08(1.32-3.28)$ & 0.002 \\
\hline $\mathrm{RCA}$ & $2.64(1.63-4.25)$ & $<0.0001$ & $2.25(1.36-3.74)$ & 0.002 \\
\hline LCX & $1.87(1.08-3.24)$ & 0.03 & - & - \\
\hline Total Agatston $\mathrm{CS}^{\mathrm{a}}$ & $275.8(197-354.6)$ & $<0.0001$ & $228.3(152.9-303.7)$ & $<0.0001$ \\
\hline Overall CAD among patients with $\mathrm{CCS} \leq 10$ & $2.03(1.10-3.73)$ & 0.02 & $1.98(1.04-3.79)$ & 0.04 \\
\hline Obstructive CAD among patients with $\mathrm{CCS} \leq 10$ & $3.56(1.36-9.31)$ & 0.009 & $4.54(1.63-12.6)$ & 0.004 \\
\hline \multicolumn{5}{|l|}{ Segments } \\
\hline No. of diseased segments ${ }^{\mathrm{a}}$ & $2.04(1.49-2.6)$ & $<0.0001$ & $1.6(1.09-2.12)$ & $<0.0001$ \\
\hline \multicolumn{5}{|l|}{ No. of segments with } \\
\hline obstructive plaques $^{\mathrm{a}}$ & $0.45(0.25-0.64)$ & $<0.0001$ & $0.38(0.18-0.57)$ & $<0.0001$ \\
\hline nonobstructive plaques $^{\mathrm{a}}$ & $1.6(1.12-2.1)$ & $<0.0001$ & $1.23(0.78-1.69)$ & $<0.0001$ \\
\hline
\end{tabular}

Data are expressed as odd ratio $(95 \% \mathrm{CI})$ or estimates of correlation $(95 \% \mathrm{CI})$ when the dependent variable was respectively categorical or continuous $\left({ }^{\mathrm{a}}\right) .{ }^{\mathrm{b}}$ After correction for baseline characteristics. 
of obstructive disease. Preliminary data show that CTCA adds prognostic information [40], and can perhaps identify lesions that are more vulnerable to rupture [41]. Intuitively, knowledge regarding the presence of severe (obstructive) disease in the proximal coronary arteries should allow for (even) more intensive management, better patient and physician compliance, and perhaps improved outcome.

Whether this is true for symptomatic patients with or without diabetes, and whether CTCA has incremental value for risk re-assessment in the absence of symptoms, which is currently not recommended, will need further study.

\section{Study limitations}

Interpretation of our results requires consideration of the limitations related to registry data, particularly in terms of a potential patient selection bias. While our results cannot be extrapolated to the general diabetic and non-diabetic population, they are hypothesis-generating and deserve future exploration in a larger, multicenter study.

Furthermore, CTCA findings were not routinely confirmed by invasive coronary angiography, or intra-coronary imaging techniques, although previous comparative studies have shown good correlation of CTCA with invasive angiography [42]. Detailed information concerning the metabolic control of patients, secondary organ damage or presence of autonomic dysfunction was unavailable.

Recent reports have even demonstrated the ability of CTCA to detect differences in coronary plaque characteristics between patients with and without DM [20-24]. However, characteristic of plaque composition has not been evaluated in the present population-based study.

In addition, the remaining concern of CTCA regards administration of contrast media and radiation exposure. However, with recent advent of new generation CT scanners and dose-modulation strategies, it will certainly be possible to limit typical effective dose values for dualsource CT and for single source CT in general to below $10 \mathrm{mSv}$ and often to below $5 \mathrm{mSv}$ [43].

Despite these limitations, the current study has the strength of including a larger patient population with respect to previous studies; further researches focused on plaque morphology and composition and on the prognostic importance of coronary stenosis are needed to better understand the role of CTCA for risk stratification in both diabetic and non-diabetic subjects.

\section{Conclusion}

CTCA in patients with diabetes and suspected CAD shows significantly more plaque and obstructive disease compared to patients without diabetes, which is independent of presenting symptoms and traditional risk factors. Contrary to non-diabetics, a low or negative calcium score does not rule out obstructive coronary artery disease in patients with diabetes mellitus.

Conflicts of interest No conflicts of interest to disclose from all Authors. The paper is original and not submitted elsewhere.

Open Access This article is distributed under the terms of the Creative Commons Attribution Noncommercial License which permits any noncommercial use, distribution, and reproduction in any medium, provided the original author(s) and source are credited.

\section{References}

1. World Health Organization (2009) Diabetes. World Health Organization, Geneva. Available via http://www.who.int/media centre/factsheets/fs312/en/. Accessed 15 Jan 2010

2. Haffner SM, Lehto S, Ronnemaa T, Pyorala K, Laakso M (1998) Mortality from coronary heart disease in subjects with type 2 diabetes and in nondiabetic subjects with and without prior myocardial infarction. N Engl J Med 339:229-234

3. Vinik AI, Ziegler D (2007) Diabetic cardiovascular autonomic neuropathy. Circulation 115:387-397

4. Achenbach S, Moselewski F, Ropers D, Ferencik M, Hoffmann U, MacNeill B, Pohle K, Baum U, Anders K, Jang IK, Daniel WG, Brady TJ (2004) Detection of calcified and noncalcified coronary atherosclerotic plaque by contrast-enhanced, submillimiter multidetector spiral computed tomography: a segment based comparison with intravascular ultrasound. Circulation 109:14-17

5. Hoffmann U, Moselewski F, Nieman K, Jang IK, Ferencik M, Rahman AM, Cury RC, Abbara S, Joneidi-Jafari H, Achenbach S, Brady TJ (2006) Noninvasive assesment of plaque morphology and composition in culprit and stable lesion in acute coronary syndrome and stable lesions in stable angina by multidetector computed tomography. J Am Coll Cardiol 47:1655-1662

6. Rumberger JA, Simons DB, Fitzpatrick LA, Sheedy PF, Schwartz RS (1995) Coronary artery calcium area by electron-beam computed tomography and coronary atherosclerotic plaque area. A histopathologic correlative study. Circulation 92:2157-2162

7. Hoff JA, Quinn L, Sevrukov A, Lipton RB, Daviglus M, Garside DB, Ajmere NK, Gandhi S, Kondos GT (2003) The prevalence of coronary artery calcium among diabetic individuals without known coronary artery disease. J Am Coll Cardiol 41:1008-1012

8. Schurgin S, Rich S, Mazzone T (2001) Increased prevalence of significant coronary artery calcification in patients with diabetes. Diabetes Care 24:1507-1508

9. Maffei E, Palumbo A, Martini C, Meijboom W, Tedeschi C, Spagnolo P, Zuccarelli A, Weustink A, Torri T, Mollet N, Seitun S, Krestin GP, Cademartiri F (2010) Diagnostic accuracy of 64slice computed tomography coronary angiography in a large population of patients without revascularisation: registry data and review of multicentre trials. Radiol Med 115:368-384

10. Butler J, Shapiro M, Reiber J, Sheth T, Ferencik M, Kurtz EG, Nichols J, Pena A, Cury RC, Brady TJ, Hoffmann U (2007) Extent and distribution of coronary artery disease: a comparative study of invasive versus noninvasive angiography with computed angiography. Am Heart J 153:378-384 
11. Expert Committee on the Diagnosis and Classification of Diabetes Mellitus (2003) Report of the expert committee on the diagnosis and classification of diabetes mellitus. Diabetes Care 26(Suppl 1): S5-20

12. Diamond GA (1983) A clinically relevant classification of chest discomfort. J Am Coll Cardiol 1:574-575

13. Morise AP, Haddad WJ, Beckner D (1997) Development and validation of a clinical score to estimate the probability of coronary artery disease in men and women presenting with suspected coronary disease. Am J Med 102:350-356

14. Agatston AS, Janowitz WR, Hildner FJ, Zusmer NR, Viamonte M Jr, Detrano R (1990) Quantification of coronary artery calcium using ultrafast computed tomography. J Am Coll Cardiol 15:827832

15. Austen WG, Edwards JE, Frye RL, Gensini GG, Gott VL, Griffith LS, McGoon DC, Murphy ML, Roe BB (1975) A reporting system on patients evaluated for coronary artery disease. Report of the Ad Hoc Committee for grading of Coronary Artery Disease, Council on Cardiovascular Surgery, American Heart Association. Circulation 51(4 Suppl):5-40

16. Shaw LJ, Raggi P, Schisterman E, Berman DS, Callister TQ (2003) Prognostic value of cardiac risk factors and coronary artery calcium screening for all-cause mortality. Radiology 228:826-833

17. King H, Aubert RE, Herman WH (1998) Global burden of diabetes, 1995-2025: prevalence, numerical estimates, and projections. Diabetes Care 21:1414-1431

18. Goraya TY, Leibson CL, Palumbo PJ, Weston SA, Killian JM, Pfeifer EA, Jacobsen SJ, Frye RL, Roger VL (2002) Coronary atherosclerosis in diabetes mellitus: a population-based autopsy study. J Am Coll Cardiol 40:946-953

19. Diamond GA, Forrester JS (1979) Analysis of probability as an aid in the clinical diagnosis of coronary-artery disease. $\mathrm{N}$ Engl $\mathrm{J}$ Med 300:1350-1358

20. Scholte AJ, Schuijf JD, Kharagjitsingh AV, Jukema JW, Pundziute G, van der Wall EE, Bax JJ (2008) Prevalence of coronary artery disease and plaque morphology assessed by multi-slice computed tomography coronary angiography and calcium scoring in asymptomatic patients with type 2 diabetes. Heart 94:290-295

21. Loffroy R, Bernard S, Sérusclat A, Boussel L, Bonnefoy E, D'Athis P, Moulin P, Revel D, Douek P (2009) Noninvasive assessment of the prevalence and characteristics of coronary atherosclerotic plaques by multidetector computed tomography in asymptomatic type 2 diabetic patients at high risk of significant coronary artery disease: a preliminary study. Arch Cardiovasc Dis 102:607-615

22. Pundziute G, Schuijf JD, Jukema JW, Boersma E, Scholte AJ, Kroft LJ, van der Wall EE, Bax JJ (2007) Noninvasive assessment of plaque characteristics with multislice computed tomography coronary angiography in symptomatic diabetic patients. Diabetes Care 30:1113-1119

23. Ibebuogu UN, Nasir K, Gopal A, Ahmadi N, Mao SS, Young E, Honoris L, Nuguri VK, Lee RS, Usman N, Rostami B, Pal R, Flores F, Budoff MJ (2009) Comparison of atherosclerotic plaque burden and composition between diabetic and non diabetic patients by non invasive $\mathrm{CT}$ angiography. Int $\mathrm{J}$ Cardiovasc Imaging 25:717-723

24. Yun CH, Schlett CL, Rogers IS, Truong QA, Toepker M, Donnelly P, Brady TJ, Hoffmann U, Bamberg F (2009) Association between diabetes and different components of coronary atherosclerotic plaque burden as measured by coronary multidetector computed tomography. Atherosclerosis 205:481485

25. Kamalesh M, Feigenbaum H, Sawada S (2007) Assessing prognosis in patients with diabetes mellitus - the Achilles' heel of cardiac stress imaging tests? Am J Cardiol 99:1016-1019
26. Rydén L, Standl E, Bartnik M, Van den Berghe G, Betteridge J, de Boer MJ et al (2007) Guidelines on diabetes, pre-diabetes, and cardiovascular diseases: executive summary. The Task Force on Diabetes and Cardiovascular Diseases of the European Society of Cardiology (ESC) and of the European Association for the Study of Diabetes (EASD). Eur Heart J 28:88-136

27. Wexler L, Brundage B, Crouse J, Detrano R, Fuster V, Maddahi J, Rumberger J, Stanford W, White R, Taubert K (1996) Coronary artery calcification: pathophysiology, epidemiology, imaging methods, and clinical implications. A statement for health professionals from the American Heart Association. Circulation 94:1175-1192

28. He ZX, Hedrick TD, Pratt CM, Verani MS, Aquino V, Roberts R, Mahmarian JJ (2000) Severity of coronary artery calcification by electron beam computed tomography predicts silent myocardial ischemia. Circulation 101:244-251

29. Raggi P, Callister TQ, Cooil B, He ZX, Lippolis NJ, Russo DJ, Zelinger A, Mahmarian JJ (2000) Identification of patients at increased risk of first unheralded acute myocardial infarction by electron-beam computed tomography. Circulation 101:850-855

30. Raggi P, Shaw LJ, Berman DS, Callister TQ (2004) Prognostic value of coronary artery calcium screening in subjects with and without diabetes. J Am Coll Cardiol 43:1663-1669

31. Schuijf JD, van der Wall EE, Bax JJ (2009) Lesions without calcium: lessons from CT angiography. Heart 95:1038-1040

32. Cheng VY, Lepor NE, Madyoon H, Eshaghian S, Naraghi AL, Shah PK (2007) Presence and severity of noncalcified coronary plaque on 64-slice computed tomographic coronary angiography in patients with zero and low coronary artery calcium. Am J Cardiol 99:1183-1186

33. Akram K, O'Donnell RE, King S, Superko HR, Agatston A, Voros S (2009) Influence of symptomatic status on the prevalence of obstructive coronary artery disease in patients with zero calcium score. Atherosclerosis 203:533-537

34. Rubinshtein R, Gaspar T, Halon DA, Goldstein J, Peled N, Lewis BS (2007) Prevalence and extent of obstructive coronary artery disease in patients with zero or low calcium score undergoing 64slice cardiac multidetector computed tomography for evaluation of a chest pain syndrome. Am J Cardiol 99:472-475

35. Nieman K, Galema TW, Neefjes LA, Weustink AC, Musters P, Moelker AD, Mollet NR, de Visser R, Boersma E, de Feijter PJ (2009) Comparison of the value of coronary calcium detection to computed tomographic angiography and exercise testing in patients with chest pain. Am J Cardiol 104:1499-1504

36. Gottlieb I, Miller JM, Arbab-Zadeh A, Dewey M, Clouse ME, Sara L, Niinuma H, Bush DE, Paul N, Vavere AL, Texter J, Brinker J, Lima JA, Rochitte CE (2010) The absence of coronary calcification does not exclude obstructive coronary artery disease or the need for revascularization in patients referred for conventional coronary angiography. J Am Coll Cardiol 55:627-634

37. Kamalesh M, Feigenbaum H, Sawada S (2007) Assessing prognosis in patients with diabetes mellitus - the Achilles' heel of cardiac stress imaging tests? Am J Cardiol 99:1016-1019

38. Giri S, Shaw LJ, Murthy DR, Travin MI, Miller DD, Hachamovitch R, Borges-Neto S, Berman DS, Waters DD, Heller GV (2002) Impact of diabetes on the risk stratification using stress singlephoton emission computed tomography myocardial perfusion imaging in patients with symptoms suggestive of coronary artery disease. Circulation 105:32-40

39. Cortigiani L, Bigi R, Sicari R, Landi P, Bovenzi F, Picano E (2006) Prognostic value of pharmacological stress echocardiography in diabetic and nondiabetic patients with known or suspected coronary artery disease. J Am Coll Cardiol 47:605-610

40. Min JK, Shaw LJ, Devereux RB, Okin PM, Weinsaft JW, Russo DJ, Lippolis NJ, Berman DS, Callister TQ (2007) Prognostic value of multidetector coronary computed tomographic angiography for prediction of all-cause mortality. J Am Coll Cardiol 50:1161-1170 
41. Motoyama S, Sarai M, Harigaya H, Anno H, Inoue K, Hara T, Naruse H, Ishii J, Hishida H, Wong ND, Virmani R, Kondo T, Ozaki Y, Narula J (2009) Computed tomographic angiography characteristics of atherosclerotic plaques subsequently resulting in acute coronary syndrome. J Am Coll Cardiol 54:49-57

42. Meijboom WB, Meijs MFL, Schuijf JD et al (2008) Diagnostic accuracy of 64-slice computed tomography coronary angiography: a prospective multicenter, multivendor study. J Am Coll Cardiol 52:2135-2144

43. Stolzmann P, Leschka S, Scheffel H, Krauss T, Desbiolles L, Plass A, Genoni M, Flohr TG, Wildermuth S, Marincek B, Alkadhi H (2008) Dual-source CT in step-and-shoot mode: noninvasive coronary angiography with low radiation dose. Radiology 249:71-80 